\title{
An anomalous RCA with ischemia on myocardial perfusion imaging
}

\author{
Liane H. van der Jagt, MD, ${ }^{a}$ Gertjan T. Sieswerda, MD, PhD, ${ }^{b}$ Mathias Prokop, \\ $M D, P h D,{ }^{c}$ and Marnix G.E.H. Lam, MD ${ }^{a}$
}

Case presentation. A 17-year-old man with no previous medical history was admitted after acute circulatory collapse due to ventricular fibrillation during a soccer game. Basic life support was performed by bystanders; after arrival of the ambulance the patient was successfully defibrillated. Physical examination after arrival at our hospital was unremarkable. A resting ECG showed an incomplete right bundle branch block, but no ST-T-wave abnormalities. No laboratory abnormalities were found.

The patient proceeded to coronary angiography, which demonstrated a dominant left system with a short main stem and normal left anterior descending and left circumflex arteries; no intraluminal abnormalities were found. The right coronary artery could not be selectively catheterized despite multiple attempts. Non-selective imaging revealed a small vessel without obstructive lesions. However, the exact anatomy of the proximal part could not be determined. Electrophysiologic studies were normal.

A coronary CT angiogram (CTA) and c-MRI were performed, CTA revealed an anomalous RCA originating from the left coronary cusp, coursing between the aorta and pulmonary artery, with significant luminal narrowing at the origin (Figure 1). The MRI showed the same abnormality and revealed no other cardiac pathology.

The patient was referred for stress-rest myocardial perfusion scintigraphy. He exercised for 16 minutes (200 Watts) and achieved $88 \%$ of the maximum predicted heart rate without electrocardiographic changes or chest pain. The myocardial perfusion images showed

From the Department of Nuclear Medicine, ${ }^{\text {a }}$ Department of Cardiology, ${ }^{\mathrm{b}}$ and Department of Radiology, ${ }^{\mathrm{c}}$ University Medical Center, Utrecht, The Netherlands.

Reprint requests: Marnix G.E.H. Lam, MD, Department of Nuclear Medicine, University Medical Center, Heidelberglaan 100, 3584 CX Utrecht, The Netherlands; M.Lam@umcutrecht.nl.

J Nucl Cardiol 2009;16:474-7

$1071-3581 / \$ 34.00$

Copyright $(\subset) 2008$ The Author(s). This article is published with open access at Springerlink.com.

doi:10.1007/s12350-008-9024-2 a small but significant area of reversible hypoperfusion in the inferior wall (Figure 2).

The patient then underwent surgical intervention. The orifice of the RCA was slit-like, with an intramural course of at least $3 \mathrm{~mm}$. The artery coursed between the aorta and pulmonary artery for at least $15 \mathrm{~mm}$. An incision was made into the ostium of the RCA, and an autologous pericardial patch was used to widen the proximal coronary artery and the orifice of the RCA. The pulmonary trunk was transected at its bifurcation and an incision was made to the left pulmonary artery. The main pulmonary artery was then anastomosed to the left pulmonary artery. The defect at the bifurcation and the distal right aspect of the pulmonary trunk were subsequently widened with a pericardial patch to prevent any stenosis. This translocation resulted in a move away from the aorta, thereby creating more space between both great vessels.

One and a half month after the surgery, the myocardial perfusion study was repeated. He exercised for 14 minutes (180 Watts) and achieved $86 \%$ of the maximum predicted heart rate without electrocardiographic changes or chest pain. The myocardial perfusion images showed no signs of ischemia nor fixed defects (Figure 3).

Discussion. The presented case illustrates the dramatic consequences of this rare congenital coronary artery anomaly. The clinical relevance and success of surgical intervention were clearly demonstrated by repeated myocardial perfusion scintigraphy.

The prevalence of congenital anomalies of the coronary arteries depends heavily on its definition and imaging modality. It is reported at $0.6 \%$ to as high as $5.6 \%{ }^{1,2}$ in the general population. An anomalous origin of the coronary artery from the opposing aortic sinus (ACAOS) is relatively rare, with a reported incidence of $0.05 \%$ to $0.9 \%^{2,3}$ for the right coronary sinus arising from the left sinus.

A coronary artery arising from the opposing aortic sinus can take each of five courses, depending on the anatomic relationship of the anomalous coronary artery to the aorta and the pulmonary trunk: (a) retrocardiac, (b) retroaortic, (c) interarterial, (d) intraseptal, or (e) prepulmonic. ${ }^{2}$ Retrocardiac, retroaortic, intraseptal, and prepulmonic courses seem to be benign, but an interarterial course reputedly carries a high risk of sudden cardiac death. Although prospective studies are lacking, 


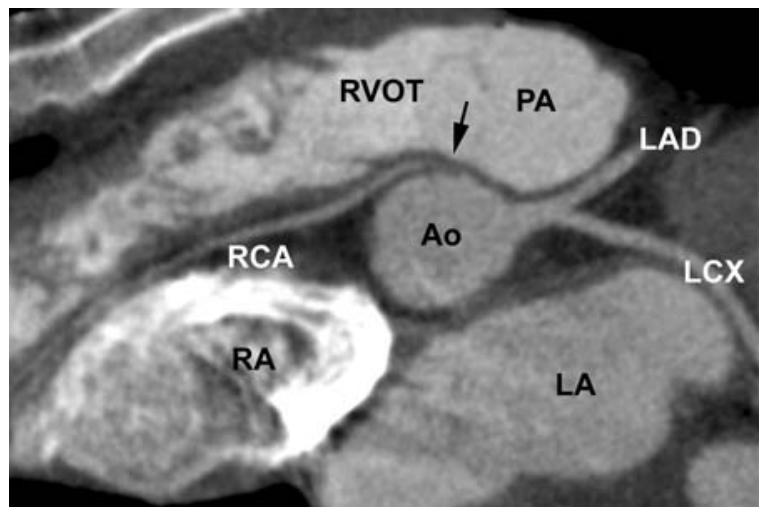

Figure 1. Malignant variant of the right coronary artery (RCA): the curved planar reformation through the main coronaries on this CT angiogram demonstrate an origin of the RCA between the aorta (Ao) and the right ventricular outflow tract (RVOT). The RCA is significantly stenosed at its origin (arrow).

some studies report sudden cardiac death in up to $30 \%$ of patients, ${ }^{4}$ usually (but not exclusively) at a young age.

A mechanism for sudden death has not been definitely established; speculation is that the coronary arterial flow is compromised by (a) compression of the coronary artery (interarterial entrapment), (b) restriction at the site of its orifice, (c) intramural proximal intussusception, or (d) kinking of the coronary artery itself.

Coronary angiography is considered to be the gold standard, ${ }^{5}$ for imaging. It is however invasive and poses risks of major complications, including stroke and death. Transthoracic echocardiography is currently the method of choice in defining the anomalous origin as well as the proximal coronary course, particularly in children. ${ }^{6}$ If the coronary artery cannot be visualized (due to significant chest wall interference and intervening pulmonary parenchyma), transesophageal echocardiography may be considered. ${ }^{7}$ The relative invasiveness of the procedure and the inability to see distal portions of the coronary tree limit its clinical applicability.

Contrast-enhanced computed tomography angiography (CTA) can also be used. It exhibits a high spatial resolution for mapping coronary anatomy but carries the risk of ionizing radiation and intravenous contrast agents. ${ }^{8}$ Magnetic resonance angiography (MRA) is costly and time consuming but does not require ionizing radiation or contrast agents. It provides a three-dimensional image of the coronary anatomy and provides

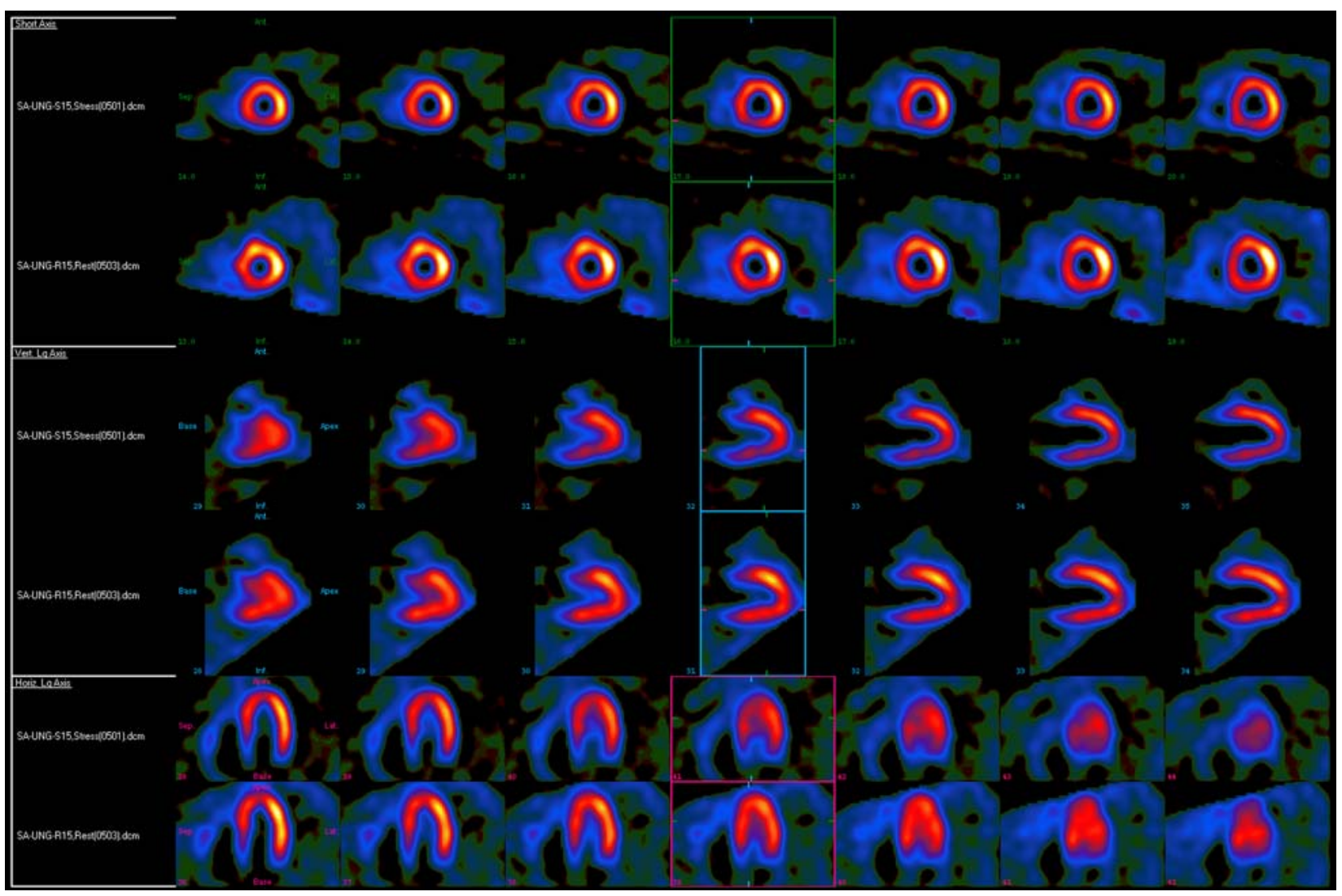

Figure 2. Technecium-99m-tetrofosmin perfusion scan showing a small but significant area of reversible hypoperfusion in the inferior wall. 


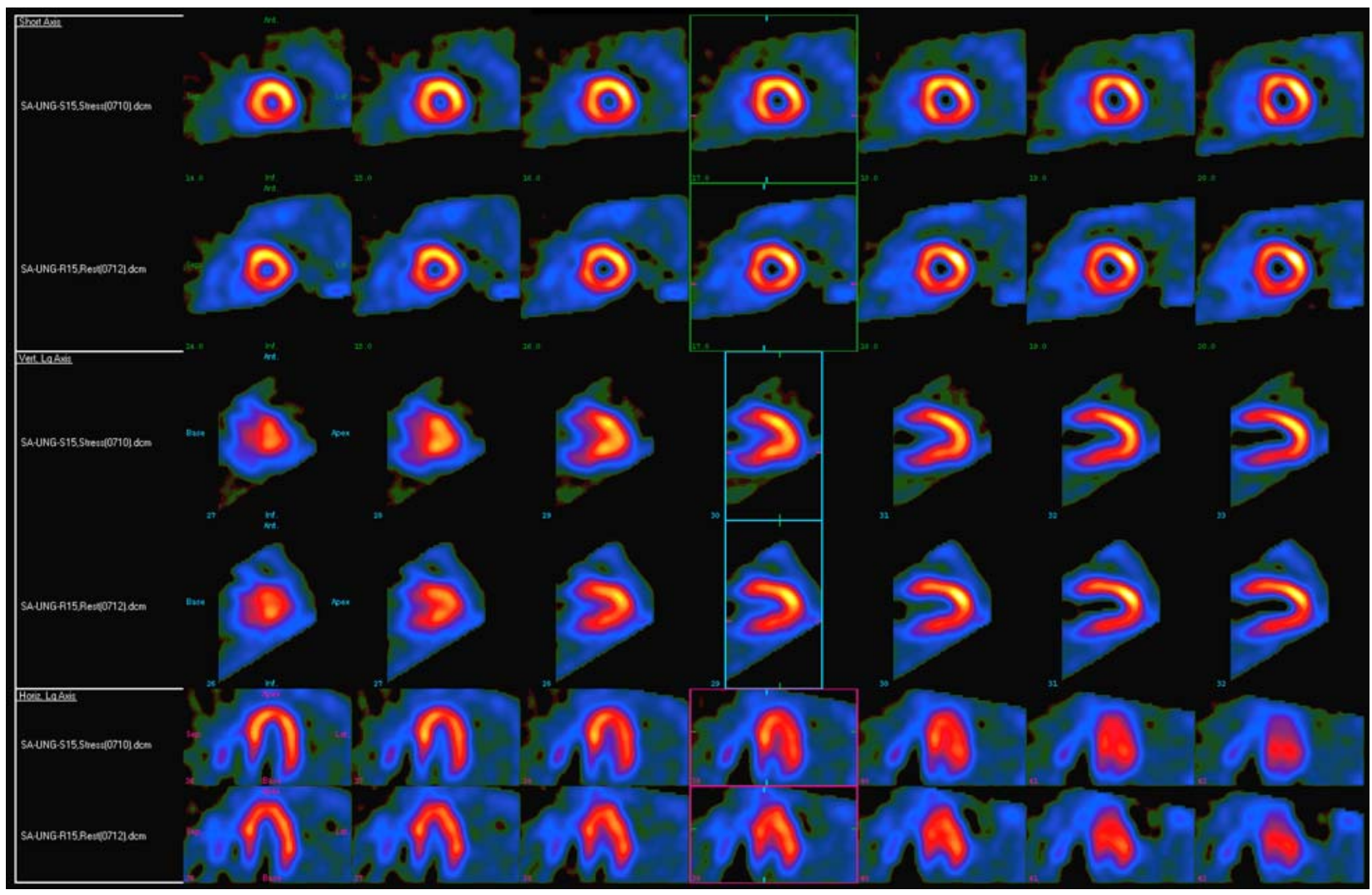

Figure 3. Repeated Technecium-99m-tetrofosmin perfusion scan showing no signs of ischemia or fixed defects.

information on adjacent anatomic structures. ${ }^{9}$ Stress-rest myocardial perfusion scintigraphy is usually required for demonstration of a functional relevance of the coronary anomaly before therapeutic intervention can take place. Although speculative, proximal (intramural) segment length, diameter, and shape assessed by intravascular ultrasound (IVUS) may provide additional information to guide need for interventional treatment. ${ }^{2}$

There are currently three treatment options: medical treatment/observation ( $\beta$-blockers), coronary stentangioplasty, and surgical repair. In our young and evidently symptomatic patient with evidence of ischemia in the territory of the aberrant coronary artery, we chose to perform surgical repair, with excellent result.

\section{Acknowledgment}

The authors have indicated they have no financial conflicts of interest.

\section{Open Access}

This article is distributed under the terms of the Creative Commons Attribution Noncommercial License which permits any noncommercial use, distribution, and reproduction in any medium, provided the original author(s) and source are credited.

\section{References}

1. Liberthson RR, Dinsmore RE, Bharti S, Rubenstein JJ, Caulfield J, Wheeler ED, et al. Aberrant coronary artery origin from the aorta: Diagnosis and clinical significance. Circulation 1974;50:774-87.

2. Angelini P. Coronary artery anomalies. An entity in search of and identity. Circulation 2007;115:1296-305.

3. Alexander RW, Griffith GC. Anomalies of the coronary arteries and their significance. Circulation 1956;14:800-5.

4. Roberts WC, Siegel RJ, Zipes DP. Origin of the right coronary artery from the left sinus of Valsava and its functional consequences: Analysis of 10 necropsy patients. Am J Cardiol 1982;49:863-8.

5. Hejmadi A, Sahn DJ. What is the most effective method of detecting anomalous coronary origin in symptomatic patients? J Am Coll Cardiol 2003;42:155-7.

6. Frommelt PC, Frommelt MA, Tweddel JS, Jacquiss RD. Prospective echocardiographic diagnosis and surgical repair of anomalous origin of a coronary artery from the opposite sinus with an interarterial course. J Am Coll Cardiol 2003;42:148-54.

7. Fernandes F, Alam M, Smith S, Khaja F. The role of transesophageal echocardiography in identifying anomalous coronary arteries. Circulation 1993;88:2532-40. 
8. Ropers D, Moshage W, Daniel WG, Jess1 J, Gottwik M, Achenbach S. Visualization of coronary artery anomalies and their anatomic course by contrast-enhanced electron beam tomography and threedimensional reconstruction. Am J Cardiol 2001;87:193-7.
9. Doorey AJ, Willis JS, Blasetto J, Goldenberg EM. Usefulness of magnetic resonance imaging for diagnosing an anomalous coronary artery coursing between aorta and pulmonary trunk. Am J Cardiol 1994;74:198-9. 